\title{
Review of Bats of Southern and Central Africa, second edition
}

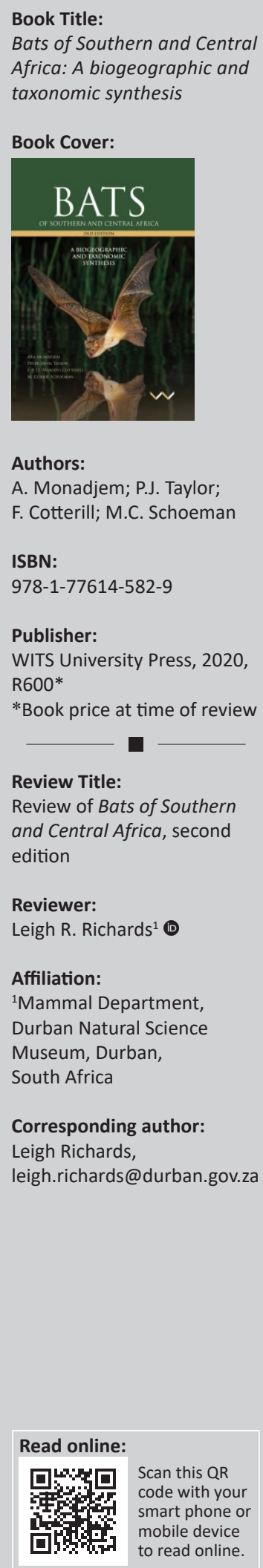

The southern Africa subregion harbours almost $10 \%$ of the global bat diversity (Mammal Diversity Database 2020). The previous edition of Bats of Southern and Central Africa provided the first comprehensive account of the biogeographical and taxonomic information on the bat species of this highly diverse Afrotropical region. It understandably became an essential reference for bat biologists and enthusiasts worldwide.

The second edition of this landmark publication provides an extensive update of the biogeography, echolocation, ecology, evolution and taxonomy of the 125 bat species detailed in the book. The explanatory text in the first five chapters has mostly remained the same, with a few exceptions, such as the expanded sections 'classification and taxonomy', 'foraging ecology and associated ecological services' and 'bat detectors'. The authors have also included a precautionary note on acceptable bat-handling practices.

As the authors point out, taxonomies have undergone radical change since the first edition, published in September 2010. The introductory text for each bat family and identification matrices are updated with the latest scientific evidence. Information on two new families, Cistugidae and Rhinonycteridae, is contained within unique colour-coded sections - a signature style of the publication. The revision includes 10 new species accounts; nine of these represent newly described or recognised species. The species accounts are unpacked in superb detail and augmented by the customary distribution maps, sonograms and colour photographs of the animal and its cranial and dental anatomy. Revised taxonomies are presented for 11 species. Care has gone into updating species distribution records and indicating instances of taxonomic uncertainty.

The museum specimen list has expanded, with 300 new records (pp. 651-694). Impressively, 73\% of the $6300+$ records were verified by the authors. It is unclear why sampling dates were added to some records and not to others. The 13-page reference list contains over 700 articles - a valuable scientific resource.

From an aesthetic perspective, the typography has improved, with the use of darker fonts and more prominent diagram labels, making the text easier to read. A major issue of the previous edition was the subpar softcover binding. The current hardcover format is a welcome improvement, especially as the publication will often be used in the field. Species distribution maps are cleanly edited and presented in vibrant colours. There is no longer a distinction between verified (red dots) and unverified occurrence records (blue dots).

I miss the predicted species distribution ranges in the former edition. Recent surveys in undersampled regions of South Africa have confirmed the extended ranges for Epomophorus crypturus, Kerivoula argentata, Laephotis botswanae and Neoromicia anchietae as predicted in the first edition (Moir et al. 2020). The authors cite the obstruction of occurrence points and geopolitical boundaries as reasons for excluding species distribution modelling outputs from the second edition. This could possibly be corrected by overlaying coloured boundary lines and points on the predicted distribution range.

Some minor issues were noted: the back cover synopsis erroneously states that the book covers 124 taxa with eight new species. Otomops martiensseni is classified regionally as 'near threatened' and not 'least concern' (Child et al. 2016). The chromosomal number of the Scotoecus hindei/albigula complex is not unknown (Nagorsen et al. 1976). Stanley (2013) highlighted the unsatisfactory images of the lancet or connecting processes of some rhinolophid bats in the previous edition. Most

How to cite this article: Richards, L.R., 2021, 'Review of Bats of Southern and Central Africa, second edition', Koedoe 63(1), a1678. https://doi.org/10.4102/Koedoe.v63i1.1678

Copyright: @ 2021. The Authors. Licensee: AOSIS. This work is licensed under the Creative Commons Attribution License. 
of these images have been replaced with more suitable photographs. Stanley (2013) also noted low-resolution photographs that rendered certain diagnostic traits, relating to dental morphology, difficult to discern. Unfortunately, this remains an impediment in the revised version. However, with global efforts towards digitising museum collections, it is almost certain that subsequent editions will contain crania and mandible photographs of higher resolution. Lastly, rapidly advancing taxonomic research means that this edition was slightly outdated by the time of publication (see the taxonomic revision of pipistrelle-like bats by Monadjem et al. 2020).

These minor matters do not detract from the impact of this revised masterpiece. I applaud the authors for their monumental efforts in producing an invaluable resource that will undoubtedly continue to enhance bat research and conservation within the region.

\section{References}

Mammal Diversity Database, 2020, Mammal Diversity Database (Version 1.31), Zenodo, viewed n.d., from http://doi.org/10.5281/zenodo.4139818

Moir, M., Richards, L.R., Rambau, R.V. \& Cherry, M.I., 2020, 'Bats of Eastern Cape and southern KwaZulu-Natal forests, South Africa: Diversity, call library and range extensions', Acta Chiropterologica 22(2), 365-381. https://doi.org/10.3161/1508 1109ACC2020.22.2.011

Monadjem, A., Demos, T.C., Dalton, D.L., Webala, P.W., Musila, S., Kerbis Peterhans, J.C. et al., 2020, 'A revision of pipistrelle-like bats (Mammalia: Chiroptera: Vespertilionidae) in East Africa with the description of new genera and species', Zoological Journal of the Linnean Society 191(4), 1114-1146. https://doi. org/10.1093/zoolinnean/zlaa087

Nagorsen, D.W., Eger, J.L. \& Petersen, R.L., 1976, 'Somatic chromosomes of three African species of bats (Chiroptera), Scotoecus hindei, Tadarida aegyptiaca and Tadarida bemmeleni', Mammalian Chromosome Newsletter 17(3), 9-12.

Child, M.F., Roxburgh, L., Do Linh San, D., Raimondo, D. \& Davies-Mostert, H.T., 2016, 'The Red List of Mammals of South Africa, Swaziland and Lesotho', South African National Biodiversity Institute and Endangered Wildlife Trust, South Africa.

Stanley, W.T., 2013, 'Bats of southern and central Africa: A biogeographic and taxonomic synthesis, second edition, Ara Monadjem, Peter J. Taylor, FPD (Woody) Cotterill \& M. Corrie Schoeman: Book review', Journal of Mammalogy 94(2), 518-551. https://doi.org/10.1644/12-MAMM-R-184.1 